\title{
LETTER
}

\section{RAD51C deletion screening identifies a recurrent gross deletion in breast cancer and ovarian cancer families}

\author{
Gioia Schnurbein ${ }^{1,2 \dagger}$, Jan Hauke ${ }^{1,2+}$, Barbara Wappenschmidt ${ }^{1,2}$, Nana Weber-Lassalle ${ }^{1,2}$, Stefanie Engert ${ }^{3}$, \\ Heide Hellebrand ${ }^{3}$, Lutz Garbes ${ }^{4}$, Alexandra Becker ${ }^{1,2}$, Guido Neidhardt ${ }^{1,2}$, Kerstin Rhiem ${ }^{1,2}$, Alfons Meindl ${ }^{3}$, \\ Rita K Schmutzler ${ }^{1,2^{*}}$ and Eric Hahnen ${ }^{1,2}$
}

RAD51C is an integral part of the DNA double-strand repair through homologous recombination, and monoallelic mutations were found in $\sim 1.3 \%$ of $B R C A 1 / 2$-negative breast cancer (BC) and/or ovarian cancer (OC) families [1]. Several studies confirmed the occurrence of RAD51C mutations predominantly in $\mathrm{BC}$ and/or $\mathrm{OC}$ families, although with varying frequencies, clearly establishing $R A D 51 C$ as a cancer-predisposing gene [2-4]. There is ongoing debate whether pathogenic $R A D 51 C$ alterations increase the relative risk for $\mathrm{BC}$ in addition to that for OC, which was estimated to be 5.88 (95\% confidence interval $=2.91$ to $11.88 ; P=7.65 \times 10^{-7}$ ) $[2]$.

Elucidating the role of $R A D 51 C$ in $\mathrm{BC}$ pathogenesis is hampered by the low frequency of clearly truncating RAD51C mutations. Deleterious alterations, as deduced by mutation type, are virtually absent in $\mathrm{BC}$-only families, and very few $\mathrm{BC}$ cases with a $\mathrm{BC} / \mathrm{OC}$ family history have been experimentally proven to carry a truncating $R A D 51 \mathrm{C} \mathrm{mu-}$ tation [1-4]. In this study, we screened for gross genomic alterations within the $R A D 51 C$ gene in $B R C A 1 / 2$-negative familial $\mathrm{BC}$ index cases, 500 of which showing a BC-only family history and 325 a BC/OC family history. Written informed consent was obtained from all patients and ethical approval was given by the Ethics Committee of the University of Cologne (07-185).

We identified a large heterozygous $R A D 51 C$ deletion encompassing exons 5 to 9 in two independent families (Figure $1 \mathrm{~A}, \mathrm{~B}, \mathrm{C}$ ). In the first (family \#1), remarkably a
BC-only family (Figure 1A), the mutation carrier was affected by early-onset and bilateral BC (age 33 years, age 39 years). The deletion was inherited from the mother who was affected by colon cancer (age 44 years). In the second (family \#2), a BC/OC family (Figure $1 \mathrm{~B}$ ), the mutation was identified in dizygotic twins, one of which was affected by early-onset BC (age 42 years) and one by early-onset OC (age 43 years). The 36,637 base pair deletion (Figure 1D,E,F) appears to be rare because we identified no further case in another large cohort by junction fragment polymerase chain reaction ( $\mathrm{BC}$ only: 1,011; BC/OC: 203). Strikingly, all three RAD51C-positive breast tumors were classified as intermediate to high grade (individual \#1-IV-2: G3, G3; individual \#2-III-6: G2 to G3), invasive ductal, and triple negative.

The early onset of $\mathrm{BC}$ in both families, the occurrence of bilateral $\mathrm{BC}$ and the triple-negative tumor phenotype resemble features closely associated with hereditary $\mathrm{BC}$ [5], and thus the presence of a clearly truncating mutation is supportive for a pathogenic role of $R A D 51 C$. Due to the low RAD51C mutation frequency, however, large collaborative studies are required to quantify the relative risk of $R A D 51 C$ alterations for $B C$ and potentially other cancer entities and, most importantly, to unravel genotype-phenotype correlations as well as genetic modifying factors that determine phenotypic variability with respect to cancer site and tumor subtype.

\footnotetext{
* Correspondence: Rita.Schmutzler@uk-koeln.de

${ }^{\dagger}$ Equal contributors

${ }^{1}$ Center of Familial Breast and Ovarian Cancer, University Hospital of Cologne, Kerpener Straße 34, 50931, Cologne, Germany

${ }^{2}$ Center for Integrated Oncology, University Hospital of Cologne, Kerpener

Straße 62, 50937, Cologne, Germany

Full list of author information is available at the end of the article
} 


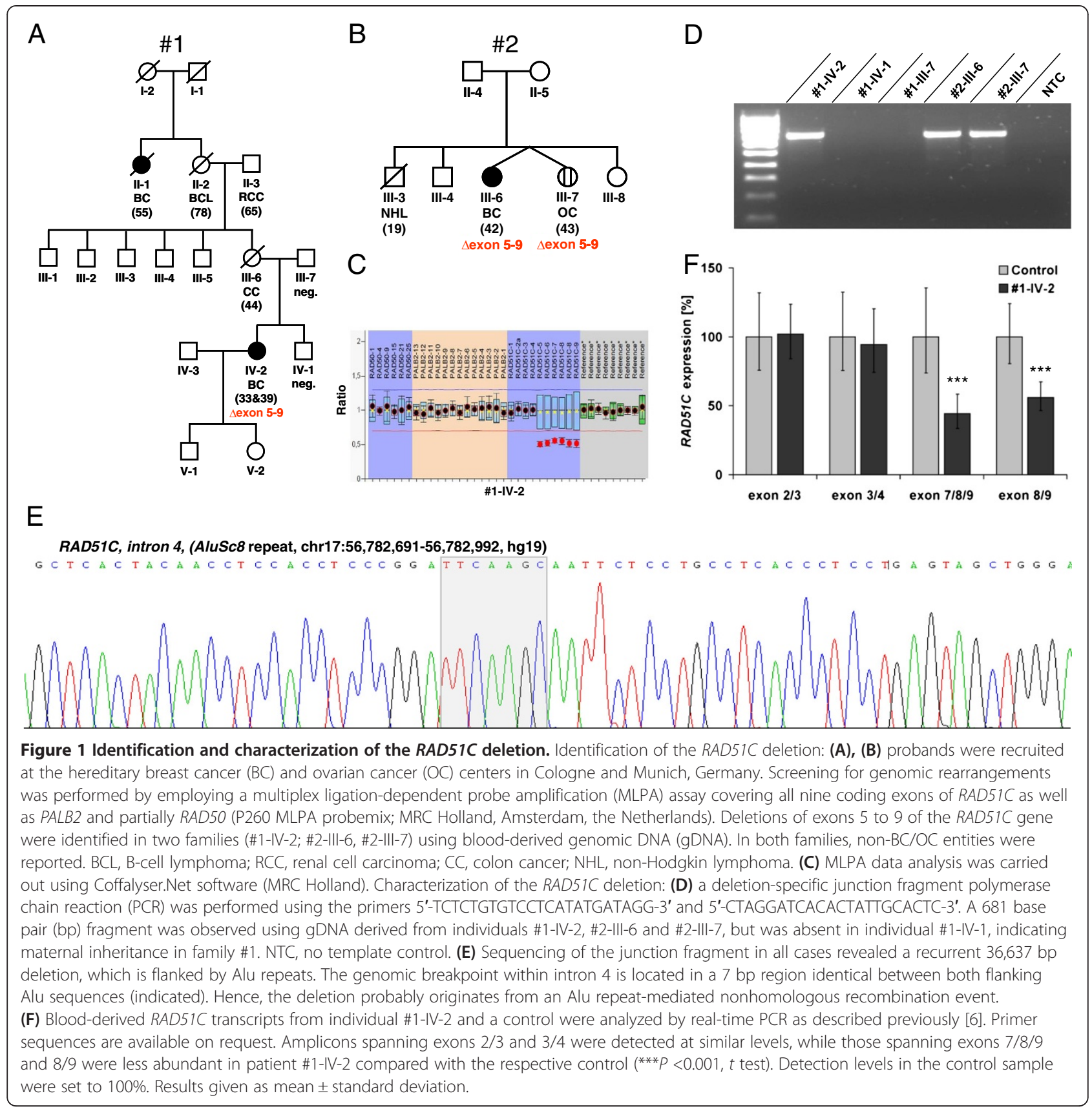

\section{Abbreviations}

BC: Breast cancer; OC: Ovarian cancer.

\section{Competing interests}

The authors declare that they have no competing interests.

\section{Authors' contributions}

BW, SE and KR participated in the study design and helped to draft the manuscript. AM, RKS and EH wrote the manuscript. GS, JH, NW-L, HH, LG, AB and GN performed the molecular genetic studies. All authors read and approved the final manuscript.

\section{Acknowledgements}

The authors apologize for omitted references. They are very thankful to all family members who participated in this study and to Sandra Kröber for excellent technical assistance. This study was kindly supported by the German Cancer Aid (grant number 109076). The funders had no role in study design, data collection and analysis, the decision to publish, or preparation of the manuscript.

\section{Author details}

${ }^{1}$ Center of Familial Breast and Ovarian Cancer, University Hospital of Cologne, Kerpener Straße 34, 50931, Cologne, Germany. ${ }^{2}$ Center for Integrated Oncology, University Hospital of Cologne, Kerpener Straße 62, 50937, Cologne, Germany. ${ }^{3}$ Department of Gynaecology and Obstetrics, Klinikum 


\section{Published: 20 Dec 2013}

\section{References}

1. Meindl A, Hellebrand H, Wiek C, Erven V, Wappenschmidt B, Niederacher D,

Freund M, Lichtner P, Hartmann L, Schaal H, Ramser J, Honisch E, Kubisch C, Wichmann HE, Kast K, Deissler H, Engel C, Müller-Myhsok B, Neveling K, Kiechle M, Mathew CG, Schindler D, Schmutzler RK, Hanenberg H: Germline mutations in breast and ovarian cancer pedigrees establish RAD51C as a human cancer susceptibility gene. Nat Genet 2010, 42:410-414.

2. Loveday C, Turnbull C, Ruark E, Xicola RM, Ramsay E, Hughes D, WarrenPerry M, Snape K, Breast Cancer Susceptibility Collaoration (UK), Evans DG ED, Gore M, Renwick A, Seal S, Antoniou AC, Rahman N: Germline RAD51C mutations confer susceptibility to ovarian cancer. Nat Genet 2012, 44:475-476. author reply 476

3. Pelttari LM, Heikkinen T, Thompson D, Kallioniemi A, Schleutker J, Holli K, Blomqvist C, Aittomaki K, Butzow R, Nevanlinna H: RAD51C is a susceptibility gene for ovarian cancer. Hum Mol Genet 2011, 20:3278-3288.

4. Thompson ER, Boyle SE, Johnson J, Ryland GL, Sawyer S, Choong DY, ConFab K, Chenevix-Trench G, Trainer AH, Lindeman GJ, Mitchell G, James PA, Campbell IG: Analysis of RAD51C germline mutations in high-risk breast and ovarian cancer families and ovarian cancer patients. Hum Mutat 2012, 33:95-99.

5. Stevens KN, Vachon CM, Couch FJ: Genetic susceptibility to triple-negative breast cancer. Cancer Res 2013, 73:2025-2030.

6. Wappenschmidt B, Becker AA, Hauke J, Weber U, Engert S, Köhler J, Kast K, Arnold N, Rhiem K, Hahnen E, Meindl A, Schmutzler RK: Analysis of 30 putative BRCA1 splicing mutations in hereditary breast and ovarian cancer families identifies exonic splice site mutations that escape in silico prediction. PLoS One 2012, 7:e50800.

\section{$10.1186 / \mathrm{bcr} 3589$}

Cite this article as: Schnurbein et al:: RAD51C deletion screening identifies a recurrent gross deletion in breast cancer and ovarian cancer families. Breast Cancer Research 2013, 15:R120 